\title{
An Emerging Theory of Human Relatedness
}

\author{
Bonnie M.K. Hagerty, Judith Lynch-Sauer, \\ Kathleen L. Patusky, Maria Bouwsema
}

Theory of human relatedness addresses a pervasive human concern, establishing and maintaining relatedness to others, objects, environments, society and self. This theory, derived from a series of inductive and deductive strategies, views relatedness as a functional, behavioral system rooted in early attachment behaviors. Individuals move through different states of relatedness including connectedness, disconnectedness, parallelism and enmeshment. Social processes that contribute to this movement are sense of belonging, reciprocity, mutuality and synchrony. Disruptions in clients' relatedness contribute to biological, psychological, and social disturbances.

T he mechanisms by which persons thread themselves into the fabric of the surrounding world have been pondered by philosophers and behavioral scientists throughout time. A pervasive human concern is establishing and maintaining relatedness to others, objects, environments, society and self, since relatedness is the context in which persons survive, develop and grow (Kohut, 1977; Gilligan, 1982; Berlin \& Johnson, 1989). We all have a need for meaningful relationships that transcend our separateness. Although previous research has examined such components of relatedness as attachment (Bowlby, 1969) and loneliness (Weiss, 1974), no broad theoretical framework for relatedness in adulthood has been proposed. The literature which addresses the nature of human relationships is often vague and disorganized with varying definitions and premises about individual concepts (Antonucci, 1990). An organizing framework for the study of relatedness is sorely lacking.

In response to the need for such a framework, our work describes an emerging theory of relatedness that is derived through both deductive and inductive strategies. This theory provides a framework from which to better understand, assess and intervene with clients experiencing difficulties in relatedness.

\section{Development of the Theory}

The theory of human relatedness evolved initially from the researchers' clinical observations that psychiatric clients seemed to demonstrate various states of connectedness and disconnectedness. It appeared that these states could be operational at any time in different contexts. For example, a psychotic, hallucinating client who could not interact with people suddenly attended to and cared for a pet. Subsequent interviews revealed that staff nurses also observed different client states of connectedness and disconnectedness. One nurse described a young woman who refused to leave her car and enter the psychiatric clinic for fear of radiation falling from the sky. The nurse offered her an umbrella and the woman immediately walked into the clinic. These accounts were developed into case studies from which concepts and their relationships emerged.

The authors began an integrative review of the literature and, to date, more than 2,000 articles on topics relevant to connectedness and disconnectedness have been systematically reviewed, evaluated and rated. More than 100 concepts under review have included attachment, alienation, loneliness and

Bonnie M.K. Hagerty, RN, PhD, Rho, is Assistant Professor, School of
Nursing; Judith Lynch-Sauer, RN, PhD, is Assistant Professor, School
of Nursing; Kathleen L. Patusky, RN, CS, MA, is a doctoral student in
nursing and psychology, all at the University of Michigan. Maria
Bouwsema, RN, MS, is Clinical Nurse Specialist, Butterworth Hospital,
Grand Rapids, Michigan. This project was supported by Biomedical
Research Funds from the University of Michigan School of Nursing
and a grant from the Office of the Vice President for Research,
University of Michigan. Correspondence to Dr. Hagerty at 2352 NIB
School of Nursing, University of Michigan, Ann Arbor, MI 48109.
Accepted for publication November 5, 1992.


social support. Concurrently, we conducted a series of four focus groups with people having no psychiatric treatment history to discuss their perceptions of connectedness and disconnectedness with self, others, society and environments.

The scope and direction of the research strategies were guided by the on-going insights emerging from these concurrent activities. This methodology is in concert with the hybrid model for concept development (Madden 1990) which includes: (a) a theoretic phase with literature review and development of working definitions; (b) a field work phase of data collection and clinical observation; and (c) an analytic phase in which findings are compared, contrasted and integrated to clarify the concept. Using this model, the initial working concepts of connectedness and disconnectedness became subsumed under the overriding theoretical construct of "relatedness."

As theory development progressed, the goal became clarification of states of relatedness (of which connectedness and disconnected are but two) and the processes or competencies necessary to achieve those states. The researchers proposed that by having a clear and comprehensive framework for understanding the nature of relatedness, nurses could intervene more quickly and appropriately with clients rather than relying only on traditional approaches. The theory was thus developed with a future vision of its usefulness for understanding client behavior and for creating and testing more effective and efficient nursing interventions.

\section{Assumptions}

As the theory emerged, we identified several basic assumptions upon which our work was based. These were as follows:

1. Human growth and development occur within the context of relatedness.

2. Persons ascribe meaning to their experiences and this is influenced by their sense of self.

3. Persons are capable of pro-activity in changing their relatedness experiences.

4. An important aspect of well-being is the affective realm.

5. Relatedness is a universal phenomenon but its expression, processes and patterns vary according to such factors as gender, race, culture and life-span development.

6. Persons experience internal and external rhythmic patterns which are interactive.

7. Persons are capable of exercising both choice and responsibility in their relatedness experiences.

8. Persons experience sensitive periods during which interventions can influence the nature of their relatedness experiences.

9. Persons experience relatedness both internally and externally.

\section{Relatedness}

The core construct of the theory is relatedness. Relatedness encompasses the experience of individuals in all types of relationships, regardless of function. The focus is on the individual's perception of the quality of the interface between that individual and any perceived external source (or referent) of relationship.

The idea of relatedness became explicit with early object relations theorists such as Klein (1964) who transcended Freud's notions of drives and instincts and began to consider more centrally, individuals' relationships with the external world and specifically, other people. Others such as Winnicott (1965) placed further emphasis on the relational field, especially that of the mother and infant, and the subsequent development of relationships with others. Attachment theory provided an additional basis for examining early parent-child processes that lead to the development and conduct of human relationships (Bowlby, 1969; Ainsworth, 1989).

Relatedness is used most often to describe interpersonal attachment. Rouslin (1973) viewed relatedness as the emotional, perceptual and cognitive capacity of a person to become involved with another person. Wynne (1984) described instrumental relatedness as an emphasis on tasks and goals rather than on the relationship and expressive relatedness as the sharing of meaningful feelings including warmth and affection in human contact. Attachment to various transitional objects or phenomena is the view of relatedness presented by Arkema (1980). A pervasive theme throughout discussions of relatedness is the assumption that its experiential essence is solace, comfort and meaningfulness (Wynne, 1984; Arkema, 1981).

We suggest that relatedness is a functional, behavioral system rooted in early attachment behaviors and patterns. Support for this position is found in the conclusion of attachment advocates that infants are genetically biased toward interaction with other people from the beginning, to a degree capable of overcoming wariness and fear (Bretherton \& Waters, 1985). Ainsworth (1989) raised the issue of the species' survival value to be found in groups. The advantage of cooperative enterprise over individual efforts led her to conclude:

It is thus reasonable to believe that there is some basic behavioral system that has evolved in social species that leads individuals to seek to maintain proximity to conspecifics, even to those to whom they are attached or otherwise bonded, and despite the fact that wariness is likely to be evoked by those who are unfamiliar... Marvin (Greenberg \& Marvin, 1982) has suggested that it be called the sociable system (Ainsworth, 1989).

The point has been made by West, Livesley, Reiffer and Sheldon (1986) that affiliation or exploration are activated only after the attachment behavioral system. Support for the view of relatedness as a species-specific behavioral system is provided by Humphrey (1976) who, in a discussion of the function of intellect, argued that social systems and social skill promote survival.

We have defined relatedness as an individual's level of involvement with persons, objects, groups or natural environments and the concurrent level of comfort or discomfort associated with that involvement. This definition: (a) extends the scope of relatedness to encompass referents such as objects and environments as well as other persons and groups; and (b) acknowledges that while relatedness can be experienced as comfortable and anxiety-reducing, it can also be experienced 


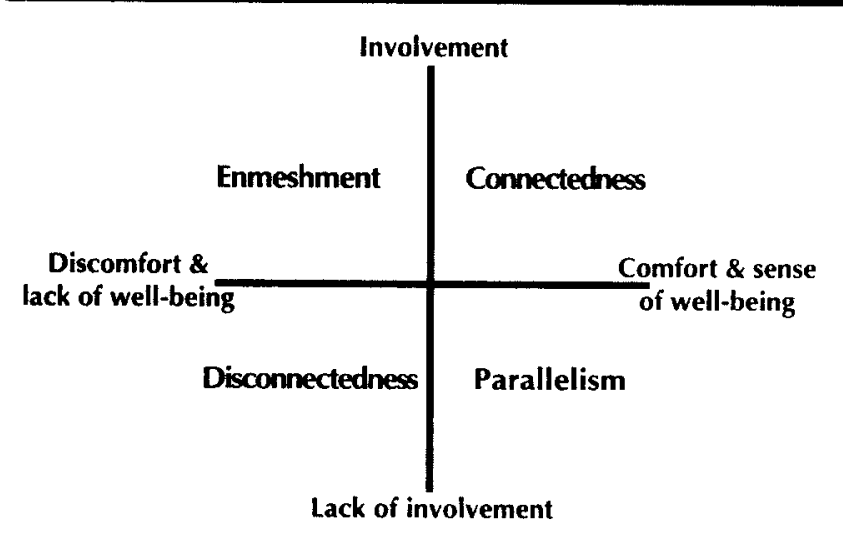

Figure 1: States of relatedness

as uncomfortable and anxiety-producing. When the two dimensions of relatedness, involvement-noninvolvement and comfort-discomfort, are placed on grid, four states of relatedness emerge: connectedness, disconnectedness, enmeshment and parallelism (Figure 1).

\section{States of Relatedness}

Connectedness. Connectedness occurs when a person is actively involved with another person, object, group or environment, and that involvement promotes a sense of comfort, well-being and anxiety-reduction. This is congruent with the conceptualization by Wynne (1984) in which attachment to others is experienced as solace and comfort. Although connectedness is used to describe relationships, the concept has not been clarified and defined.

Gilligan (1982) and Keller (1986) described connectedness as participation or involvement in a relationship. Miller (1976) discussed emotional connection as active interchanges with others. Describing attachment, which may be a necessary antecedent for connectedness, Bowlby (1969) posited that infants need proximity to a caretaker as a means for anxiety reduction. These perspectives are congruent with the proposition that connectedness is one component of a necessary, relational behavioral system.

Disconnectedness. Disconnectedness is experienced when a person is not actively involved with another person, object, group or environment, and that lack of involvement is associated with discomfort, anxiety and a lack of a sense of well-being. Connotations of lack of involvement associated with psychological pain have been subsumed as loneliness (Weiss, 1974), estrangement, social isolation (Anderson, 1981) and alienation (Dean, 1961). While these concepts tend to imply absence or loss of a social network or attachment figure, disconnectedness, as an affective state experienced by the person, may involve neither. Gupta (1971) described a disintegrative type of state in which persons feel pain and anxiety, isolation and emptiness. The researchers view disconnectedness as most similar to Anderson's (1981) descriptions of emotional estrangement and social estrangement; the lack of intimacy associated with anxiety and the lack of relatedness to a social environment.
Parallelism. Parallelism occurs when a person's lack of involvement with another person, object, group or environment is experienced as comfortable and as promoting a sense of well-being. While lack of involvement is often viewed by clinicians as isolative, lonely, and ultimately detrimental, there is support for the importance of parallelism in replenishing emotional and physical health. Birtchnell (1987) reminded us that mutual respect for others' needs to be separate is essential. Winnicott (1965) noted that the capacity to be alone was a sign of maturity. The conception that disengagement or lack of involvement can promote well-being is reinforced by Engel and Schmale's (1972) concept of conservation-withdrawal in which biological survival is supported by disengagement and inactivity. Applying this to psychosocial needs, Ironside (1980) posited that a similar process is vital to psychological renewal and growth. Likewise, Berezin (1980) suggested that some forms of isolation, or lack of involvement, may not be pathological but may contribute to creativity, rest, and focused concentration.

Enmeshment. Persons experience enmeshment when they are involved with others, objects, groups, or environments and this involvement is coupled with discomfort and anxiety. Enmeshment has been used to describe a narrowly regulated, homeostatic system that is occupied by fused individuals (Klugman, 1976). Family therapists such as Bowen (1978) have described the fused family system in which members are unable to communicate. This type of conceptualization assumes a static pattern of relational behavior, noting that enmeshment is indicative of fusion, or personal lack of differentiation. Many theories that address enmeshment focus on the dynamics of the individual involved in enmeshment rather than on the interchange between the individual and the other person, object, group or environment. For example, Berlin and Johnson (1989) identified characteristics such as coercion by others, the need for self-sacrifice and submission and the lack of sense of self as dynamics of enmeshment. Birtchnell (1987) described various types of receptiveness, the inclination to assume a recipient attitude towards others and characterized by a fear of assuming responsibility. Enmeshment, as viewed by the authors, emphasizes the perceived involvement and quality of the interchange between a person and a specific referent.

Characteristics of the States. We the following characteristics about these four states of the relatedness behavioral system. First, at any given point, each state is experienced in relation to a specific referent: others (interpersonal), objects, groups and social institutions (social) and environments (natural and man-made). In addition to other persons and animate objects, people enter into interactions or transactions with natural phenomena. Humphrey (1976) noted the importance of transactions with non-human things, including plants and dolls.

Second, at any point, persons may experience varying states of relatedness with respect to several different domains. For example, a person may function in a state of parallelism with respect to his or her spouse by not wishing to think about or be with that spouse, but be quite connected with a natural environment by spending a weekend alone at the beach, experiencing renewal and comfort from the sun and sand. 
Third, people do not exist inherently in one state or another but move through all of the states over time in relation to specific people, objects, groups or environments. What appears to be important is the pattern of movement throughout these states, including patterns of duration, intensity and frequency. Indeed, the capacity for movement may be a greater sign of health than consistency within one state.

\section{Relatedness Competencies}

As the four states of relatedness emerged, we began to look more closely at those phenomena that seemed to contribute to and actually comprise the various states of relatedness. Again, using data from the integrative research review, observations and case studies, interviews with psychiatric nurses, and focus group findings, we identified four major processes or social competencies involved in establishing and promoting relatedness states: sense of belonging, reciprocity, mutuality and synchrony.

Sense of Belonging. This is personal involvement in a system or environment so that persons feel themselves to be an integral part of that system or environment (Hagerty et al., 1992). A system can be a relationship or organization and an environment can be natural or cultural. This definition is based on the work of Anant (1969) who posited relationships between belonging, anxiety and self-sufficiency. In spite of Anant's work, much of the literature that addresses belonging is narrative rather than empirical. Maslow (1954) identified belonging as a basic human need, ranking it third in his hierarchy. Anecdotal accounts of belonging are provided by Dasberg (1976) and Kestenberg and Kestenberg (1988), among others. All of the descriptions of belonging emphasize its important role in object relationships.

Reciprocity. Reciprocity is the individual's perception of an equitable, alternating, interchange with another person, object, group or environment that is accompanied by a sense of complementarity. Reciprocity has been used to describe the nature of exchange in relationships (Antonnucci \& Jackson, 1990). The norms and characteristics of reciprocal social exchange vary depending on the nature of the relationship, however, equal exchange is usually viewed as optimal and imbalances as aversive (Greenberg \& Shapiro, 1971). Wynne (1984) noted that the giving and taking involved in reciprocity should be experienced as sincere, welcomed and freely initiated. The common theme throughout descriptions of reciprocity is the quality and intensity of exchange.

Mutuality. Mutuality emerged as the third relatedness competency. Mutuality is a term that has been used widely with little attention to definition and clarification. Riggs (1978) described mutuality as the conscious acceptance by both parties in a relationship of the goals, modes and codes of the interchange. Describing marital relationships, Stephen and Markham (1983) defined mutuality as the extent to which couples have developed a conjoint or relational world-view. This coincides with Tronick's (1977) perspective that mutuality is the achievement of intersubjectivity. Buber (1937) discussed mutuality as a co-constituted reality where each person is made present by the other. The sharing of characteristics, sentiments or goals is Wynne's (1984) conception of mutuality. However, Wynne noted that pseudomutuality, an absorption in fitting together at the expense of maintaining separate personal identities, is sometimes confused with mutuality. He added that, in mutuality, each person has the ability to tolerate divergence of self-interests and differences.

Recurrent themes in the various discussions of mutuality are shared commonalities and validation of relationship participants. We define mutuality as the experience of real or symbolic shared commonalities of visions, goals, sentiments, or characteristics, including shared acceptance of differences, that validate the person's world-view.

Synchrony. Synchrony, the fourth relatedness competency, has been used generally to describe rhythmic patterns. We define synchrony as a person's experience of congruence with his or her internal rhythms and external interaction with persons, objects, groups or environments. Three themes of synchrony emerged from the theory development activities: psychological or spiritual rhythms and occurrences; physiological patterns and rhythms; and mother-infant or human interaction rhythms. These themes of synchrony support the researchers' conceptualization of the competency as a sense of shared movement through space and time.

Psychological or spiritual rhythms have been described best by Jung (1960) whose notion of synchronicity considers events that occur with certain timing and patterns but with no apparent rational connection or rational meaning. Physiological rhythms that have been demonstrated to affect behavior include such phenomena as circadian rhythms (Wehr \& Goodwin, 1983), sleep patterns (Wehr, 1990), and light/seasonal patterns (Lewy et al., 1990). Linking rhythms of major life events with biological rhythms, Ehlers, Frank and Kupfer (1988) examined how disruption of social rhythms triggers biological dysfunction that affects mental health. Human interaction has been examined by measuring aspects of rhythmic patterns evident in the activity between two persons. Kestenberg and Buelte (1977) referred to the importance of harmonizing patterns to prevent isolation and to promote tension relief. Penman et al. (1983) discussed behavioral synchrony as repetitive cycles of attention and non-attention where attention promoted social engagement and non-attention led to disengagement. Empathic attunement through which the parent integrates and modulates for the baby has been discussed by Kohut (1977). Synchrony has also been used to describe the quality of mother-infant interaction (Karger, 1979). Rogers' (1985) work on life rhythms and patterns in the person-environment interaction encompasses both psychological and physiological phenomena that affect human development and change.

\section{The Relationships of States and Competencies}

We propose that the extent to which the relatedness competencies are evident in any particular relationship with other people, groups, objects or environments will influence and determine the person's state of relatedness. More specifically:

1. A person will experience connectedness with respect to a particular relationship when that person experiences higher levels of sense of belonging, reciprocity, mutuality and synchrony. 
2. A person will experience disconnectedness with respect to a particular relationship when that person experiences low levels of sense of belonging, reciprocity, mutuality and synchrony.

Hypothesizing the extent to which the elements of relatedness appear in the states of parallelism and enmeshment requires additional theoretical and descriptive work. However, we anticipate that unique patterns of these four elements will be evident as we continue to clarify and refine these relational states.

\section{Relevance for Nursing}

Relatedness is a central idea in nursing, applicable to all specialties. Disruptions in clients' relatedness competencies or movement through the various relatedness states may contribute to biological, psychological and social disturbances. Likewise, these biopsychosocial disturbances may result in responses that influence the states and competencies of relatedness. Relatedness is also pertinent to implementation of the nurse-client relationship. As an avenue for interaction, relatedness, and specifically its competencies, offer the medium through which nurses may initiate and maintain the most helpful and efficient relationships with their clients.

Theory of human relatedness provides a framework for clarifying, teaching and researching client behavior. Theory development for improvement of practice is one of the goals of nursing. Through identification of phenomena, definition of concepts and their characteristics, and generation of theoretical propositions, nurses will be able to conceptualize and develop practice approaches from a scientific foundation. There is a gap in the theoretical underpinnings of our practice that involves an emphasis on interaction and client behavior (Hall, 1988). This deficiency demands systematic theory generation and subsequent research on the concepts and theoretical statements to advance nursing science in this area.

The theory also assists nurses to examine approaches, including nurse-client relationships, assessment and interventions, and to test practice innovations. Changes in health care and technology demand innovative practice approaches that address higher client acuity, shortened lengths of hospital stay, community-based care and more complex client problems. Nurses are reexamining the basics, reflecting on how they approach their practice. On review are the long-standing assumptions, frameworks, interventions and outcomes to which nursing has so long adhered. Adjustments in old paradigms that emphasized time with the client and more control of client circumstances, no longer seem to work; new paradigms for practice are necessary.

Relatedness provides a unique basis for assessing and intervening with clients. Future questions that can be asked are: "Does the client have a sense of belonging with any person, group, object or environment? If not, how can we assist with that? Does the client experience reciprocity in relationships with others? What effect is this having and how can reciprocity be facilitated?"

The notion of relatedness and its various states allows the clinician and researcher to reframe psychological disorders and behaviors and to examine patterns of relating from a more adaptive and fluid perspective. This framework can also assist in clarifying the processes of social support that mediate responses to illness and stress. 다래

\section{References}

Ainsworth, M.D.S. (1989). Attachments beyond infancy. American Psychologist, 44(4), 709-716.

Anant, S.S. (1969). A cross-cultural study of belongingness, anxiety, and self-sufficiency. Acta Psychologia, 31(4), 385-393.

Anderson, C.J. (1981). Enhancing reciprocity between mother and neonate. Nursing Research, 30, 89-93.

Antonucei, T.C. (1990). Social supports and social relationships. In R.H. Binstock \& L.K. George (Eds.), Handbook of aging and the social sciences (3rd ed.) (111-128). San Diego: Academic Press.

Antonnuci, T.C., \& Jackson, J.S. (1990). The role of reciprocity in social support. In I.G. Sarason, B.R. Sarason, \& G.R. Pierce (Eds.), Social support: An interactional view (205-226). New York: John Wiley.

Arkema, P.H. (1981). The borderline personality and transitional relatedness. American Journal of Psychiatry, 138(2), 172-177.

Berezin, M.A. (1980). Isolation in the aged: Individual dynamics, community and family involvement. Journal of Geriatric Psychiatry, 13(1), 5-18.

Berlin, S., \& Jobnson, C.G. (1989). Women and autonomy: Using structural analysis of social behavior to find autonomy within connections. Psychiatry, 52(1), 79-95.

Birtchnell, J. (1987). Attachment-detachment, directiveness-receptiveness: A system for classifying interpersonal attitudes and behavior. British Journal of Medical Psychology, 60, 17-27.

Bowen, M. (1978). Family therapy in clinical practice. New York: Jason Aronson, Inc.

Bowlby, J. (1969). Attachment and loss, vol I. New York: Basic Books, Inc.

Bretherton, I., \& Waters, E. (Eds). Growing points of attachment theory and research: Monograph of the Society for Research in Child Development. (1-2) Serial No 209; 1985.

Buber, M. (1937). I and thou. R. Smith (Trans.). New York: Schribner's.

Dasberg, H. (1976). Belonging and loneliness in relation to mental breakdown in battle. Israeli Annals of Psychiatry and Related Disciplines, 14(4), 307-321.

Dean, D.C. (1961). Alienation: Its meaning and measurement. American Sociological Review, 26, 753-775.

Ehlers, C.L., Frank, E., \& Kupfer, D.J. (1988). Social zeitgebers and biological rhythms. Archives of General Psychiatry, 45(10), 948-952.

Engel, G.L., \& Schmale, A.H. (1972). Conservation-withdrawal: A primary regulatory process for organic homeostasis. In CIBA (Ed.) Physiology, emotion and somatic illness (57-85). Amsterdam: CIBA Foundation.

Gilligan, C. (1982). In a different voice. Cambridge, MA: Harvard University Press.

Greenberg, M.S., \& Schapiro S.S. (1971). Indebtedness: An adverse aspect of asking for and receiving help. Sociometry, 34, 290-301.

Gupta, M. (1971). An interruption in loneliness: The use of concrete objects in the promotion of human relatedness. Journal of Psychiatric Nursing and Mental Health Services, 9(4), 23-27.

Hagerty, B.M., Lynch-Sauer, J., Patusky, K., Bouwsema, M., \& Collier, P. (1992). Sense of belonging: A vital mental health concept. Arehives of Psychiatric Nursing, 6, 172-177.

Hall, B.A. (1988). Specialty knowledge in psychiatric nursing: Where are we now? Archives of Psychiatric Nursing, 2, 191-199. 
Humphrey, N.K. (1976). The social function of intellect. In P.P.G. Bateson \& R.A. Hinde (Eds.), Growing points in ethology, (303-317). London: Cambridge University Press.

Ironside, W. (1980). Conservation-withdrawal and action-engagement: In a theory of survivor behavior. Psychosomatic Medicine, 42(1), 163-175

Jung, C.G. (1960). Synchronicity: An accusal connecting phenomenon. In W. McGuire (Ed.), The structure and dynamics of the psyche, (48-72). New York: Princeton University Press.

Karger, R.H. (1979). Synchrony in mother-infant interactions. Child Development, 50, 882-885.

Keller, C. (1986). From a broken web. Boston: Beacon Press.

Kestenberg, M., \& Kestenberg, J.S. (1988). The sense of belonging and altruism in children who survived the holocaust. Psychoanalytic Review, 75(4), 533-560.

Kestenberg, J.S., \& Buelte, A. (1977). Prevention, infant therapy, and the treatment of adults. 1. Toward understanding mutuality. International Journal of Psychoanalytic Psychotherapy, 6, 339-367.

Klein, M. (1964). Contributions to psychoanalysis, 1921-1945. New York: McGraw-Hill.

Khygman, J. (1976). Enmeshment and fision. Fami y Process, 15(3), 321-323.

Kohut, H. (1977). The restoration of the self. New York: International Universities Press.

Lewy, A.J., Sack, R.L., \& Singer, C.M. (1990). Bright light, melatonin, and biological rhythms in humans. In J. Montplaisir \& R. Godbout (Eds.), Sleep and biological rhythms, (99-128). New York: Oxford University Press.

Madden, B.P. (1990). The hybrid model for concept development: Its value for the study of therapeutic alliance. Advances in Nursing Science, 12(3), 75-87.

Maslow, A. (1954). Motivation and personality. New York: Harper.

Miller, J.B. (1976). Towards a new psychology of women. Boston: Beacon Press.

\section{Foundation for Health Services Research}

\section{Announces Picker/Commonwealth Scholars Program}

The Foundation for Health Services Research (FHSR) is pleased to announce the second grant cycle of the Picker/Commonwealth Scholars Program.

Established in 1992 by The Commonwealth Fund, the Scholars Program provides fellowships of up to $\$ 100,000$ over a two-year period to faculty members early in their academic careers who are committed to studying patient experiences with health care.

The program's objectives are to: encourage faculty members to undertake research that examines how the characteristics of the patient, the provider, the delivery setting, the process of care and medical care practices interact and impact on the patient's experience with health care; and, to understand how those findings can be translated into improvements in the quality, process and outcomes of care.

Up to five scholars will be selected annually.

The deadiline for applications is February 14, 1994. For information and an application package, please contact:

Foundation for Health Services Research 1350 Connecticut Ave., N.W. Suite 1100

Washington, DC 20036

Tel: (202) 223-2477
Penman, R., Meares, R., Baker, K., \& Milgrom-Friedman, J. (1983). Synchrony in mother-infant interaction: A possible neurophysiological base. British Journal of Medical Psychology, 56, 1-7.

Riggs, B.C. (1978). System C: An essay in human relatedness. American Journal of Psychotherapy, 32(3), 379-392.

Rogers, M.E. (1985). Introduction to the theoretical basis of nursing. Philadelphia: F.A. Davis Co.

Rouslin, S. (1973). Relatedness in group psychotherapy. Perspectives in Psychiatric Care, 11(4), 165-171.

Schecter, D.E. (1973). On the emergence of human relatedness. In E.G., Witenberg (Ed.), Interpersonal explorations in psychoanalysis, (17-39) New York: Basic Books.

Stephen, T.D., \& Markham, H.J. (1983). Assessing the development of relationships: A new measure. Family Process, 22(1), 15-25.

Tronick, E.D., Als, H., \& Brazelton, T.B. (1977). Mutuality in motherinfant interaction. Journal of Communication, 27(2), 74-79.

Wehr, T.A., \& Goodwin, F.K. (1983). Biological rhythms and psychiatry. Pacific Grove, CA: Boxwood Press.

Wehr, T.A. (1990). Effects of wakefulness and sleep on depression and mania. In J. Montplaisir \& R. Godbout (Eds.), Sleep and biological rhythms, (42-86). New York: Oxford University Press.

Weiss, R.S. (1974). Loneliness: The experience of emotional and social isolation. Cambridge, MA: MIT Press.

West, M., Livesley, W.J., Reiffer, L., \& Sheldon, A. (1986) The place of attachment in the life events model of stress and illness. Canadian Journal of Psychiatry, 31, 202-207.

Winnicott, D.W. (1965). The maturational process and the facilitating environment. New York: International Universities Press.

Wynne, L.C. (1984). The epigenesis of relational systems: A model for understanding family development. Family Process, 23(3), 297-318.

\section{Intercollegiate Centerfor Nursing Education of Eastem Washington University, Washington State University and Whitworth College}

Applications and nominations are invited for nine-month Tenure Track Nursing Faculty Positions available August, 1994 in Spokane, Washington for Assistant Professor or higher depending upon qualifications. Masters in nursing and doctorate in appropriate field required. Preference given to candidates as follows:

Adult Nursing: With clinical experience as nurse practitioner or clinical nurse specialist in oncology, metabolic/endocrine, nephrology, and/or care of individuals in non-institutionalized settings.

Community Health Nursing: With experience and participation in public health sciences and public health nursing.

Maternity/Women's Health: With expertise in communitybased practice.

Psychiatric/Mental Health: With experience in both inpatient and community-based practice.

Send resume or nominations by February 1, 1994 to:

Search Committee

Intercollegiate Center for Nursing Education

W. 2917 Ft. George Wright Drive

Spokane, WA 99204

(509) 325-6132

Washington State University is an EOIAA employer and educator. Protected group members are encouraged to apply. 